And I bold that (in this case at least) the absence of any portion of the svstolic murmur at the apex is a proof that no vibrations of the valve were concerned in its production, for if they had been, what was to prevent their conduction to the apex in the same way as the tension-sound?

$$
\text { (To be concluded.) }
$$

ON

\section{A NEW SYSTEM OF ABSCESS DRAINAGE BY SPIRAL WIRE TUBES.}

Bx ROBERT ELLIS, Esq.

OBSTETRIC SURGEON TO THE CHELSEA, BROMPTON, AND BELGRAVE DISPENSARIES.

So many years have passed since I first began to use the wire tubes which I propose to describe in this article, that it scarcely occurred to me to publish any account of them, until, on recently showing their excellent performance to several high surgical authorities, I was urged to make them more generally known.

It is about eight years since a lady applied for relief for great pain and tenderness over the pubes and the hypogastrium generally. Her febrile condition, loaded tongue, and cachectic aspect led me to suspect, in connexion with these symptoms, the existence of some collection of pus in or near the uterus; and on vaginal examination, I found this organ distended with fluid, and the cervix absolutely impervious. Fixing the cervix, I passed a long trocar throughout its length, and gave exit to nearly half a pint of horribly fetid pus. But since this condition of things could not be allowed to repeat itself, it then occurred to me that if I could devise some very flexible tube the sides of which could not be compressed so as to make it impervious, and if it could be retained in the cervical canal, good service would be thereby rendered. My first attempt was with tubes of caoutchouc; but these were quite useless, for the least angular bend stopped them up, and their elastic walls yielded at once to a very slight pressure from without. I then tried a tube made of soft tinfoil; but in the tubular form this metal became quite rigid, and, if bent, the tubes were as apt to become closed up as the others. The idea then occurred to me to make a tube of very fine hard brass wire, by coiling it regularly and evenly over a fine steel rod. The tube was readily made, and its success was perfect. It was elastic in the highest degree ; it could even be tied into a knot without destroying its patulousness; its flexibility would follow the wanderings of any sinus, however crooked; and its sides, being slightly open, permitted the secretions of the cavity it penetrated, and the canal in which it lay, readily to pass through. I procured several of these, of different lengths and sizes, and, fitting one of them to the artificial canal made in the cervix uteri, I had the satisfaction of seeing it day by day drain the diseased uterine cavity of its pus; and in a very little time the patient made an excellent recovery, and has since continued perfectly well.

The success of this system of drainage led me to apply the same tubes to a variety of other cases; and I hope shortly to publish some account of their remarkable value, especially in cases of dysmenorrhoea arising from mechanical obstruction of the cervical canal. I have also successfully used them, in some displacements of the uterus, for rectifying the bent state of the cervix which frequently accompanies these malpositions; and in a very opposite class of cases to those of the dysmenorrhoal type-viz., the menorrhagic,-in which they have done valuable service in affording a safe and certain outlet for intra-uterine injections. It is to the approral of Mr. Paget of the application of these tubes to the drainage of deep chronic abscesses generally that the idea of submitting them to the readers of THE LANCET is chiefly due.

These tubes, as I have mentioned, consist simply of a closely wound coil of wire, and resemble exactly the springs used by dentists for supporting artificial teeth, or those used by bell-hangers to preserve the due tension of their wires. They are simply spiral springs made of brass or copper wire, of different degrees of tenuity and elasticity. In ob- stetrical practice I employ only the very fine hard brass wire, the finest I can procure; for I find this makes the best tubes for my special purposes. But for ordinary abscesses in other regions of the body very fine copper wire may be used; it is softer, and exerts very little strain on the tender structures through which it has to pass. It is also finer than the other, and thus can be adapted to long, narrow sinuses, to every bend of which the tube will easily accommodate itself. It is a mere superstition that the copper or the brass do any mischief as metallic substances to the canal in which they lie, or constitutionally. I have used hundreds of these tubes without the smallest evidence of harm due to the metals of which they are composed. But, if it be thought desirable, they may be electro-gilded in a few minutes by plunging them in a hot solution of eyanide of gold, with the aid of a battery and a piece of gold foil.

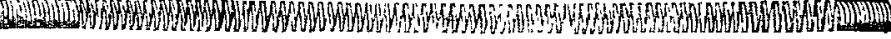

The manufacture of the tubes is thus managed; and its extreme simplicity ought to enable every surgeon to make them without recourse to the instrument maker. I have always made my own, and thus exactly adapted them to the peculiarities of the individual case. If the surgeon possess a common lathe, they may be made, literally, in a minute. But they can also be made by hand, only they are less even and neat in appearance. I take (for the lathe) a number of common knitting needles of different sizes, cut off the required length, square one end of each after tempering it down in the flame of a candle, and "centre" the other. This forms the tool, or " maundrill," on which the wire is to be coiled. Being fixed in a chuck at one end, and adapted to the lathe-centre point at the other, it is ready for work. The wire is fastened to a pin in the chuck, and the lathe is put in motion: the slow motion is used. The wire, being firmly held in the hand, is drawn by the revolution of the axis upon itself, and thus coils itself automatically, and by a very few revolutions of the wheel the tube is finished. When made "by hand," the steel rod must be firmly fixed at one end in a vice, and the wire then slowly and carefully wound over it to the desired length. Very good tubes can be made in this way, though it is inferior to the other. By a strong pair of scissors or a wire nipper, the tubes can be cut to any size. In order to make them very flexible, it is better to draw them out a little at each end; the spirals are thus slightily separated from each other, and the walls of the tube by this means readily permit the percolation of pus or other fluids to go on through their sides. Care must be taken to bend in slightly the terminal coil of the tube, so that the point of the wire may not catch in the tissues through which it is passed.

Their method of application is as follows:-For the uterine cervical canal it is necessary to fix the cervix by a tenaculum, and gently to pass up the tube mounted on a uterine sound; the free end then lies in the upper part of the vagina. It is useful to slip a morsel of vulcanised tube over this free extremity, so as to prevent its abrading the posterior vaginal wall. For an ordinary abscess they may be introduced on a probe or director, and often without any such assistance, by a spiral, coaxing sort of motion. They are retained easily in situ by tying a piece of silk over the free end, and fastening this to the skin by a strip of adhesive plaster. A loose soft pad of cotton wool should then be placed over the tube, and it will be found to do its work with the greatest regularity until the abscess ceases to secrete any more pus.

As in the tracheotomy tubes, it is convenient to have a double tube in many cases, the inner one being a size or two smaller than the outer. This may be withdrawn and cleansed, and then replaced. They will require changing generally about once a fortnight, but I have seen no harm arise from a much longer stay.

I do not propose to encumber the pages of The Lancer with a recital of the many cases in which I have found these tubes render invaluable service. I believe the drainage system here introduced to be so simple and practical that no surgeon who once takes to its employment will be disappointed with the results; but $i_{\alpha}^{c}$ there be any point requiring further explanation, I should be happy to give it to any medical man who may wish for it. The following note of Mr. Paget's will probably induce some of my professional brethren to give this plan of drainage a fair trial. 
“Dear Mr. Ellis,-I have now used your spiral-wire drainage-tubes in cases sufficient to prove to me that they hare these following adrantages over any other means of drainage that I have set seen:-

"They can be placed in sinuses of rery small diameter, and with equal advantage whether the sinus have one or more openings.

"Their bore is not diminished by bending them to any angle.

They cannot be flattened or shut up by contraction of the orinice of the sinus.

"They can be inserted with very great facility; and can be worn for any length of time, in fit cases, without causing irritation.

"They are cleanly, and excite no decomposition in pus or other fluids. "Sincerely yours, "JAMres PAGET."

It mar be convenient that I should add that the tubes may be procured, of various sizes and lengths, from Messrs. Mayer and Meltzer, of Great Portland-street, W. Sloane-street, July, 1869

SOME OBSERVATIONS

\section{ON THE OPERATIONS FOR EXTRACTION OF STONE PERFORMED AT THE LEICFSTER INEIRMARY,}

\section{CONTAINING A STATISTICAL ACCOUYT OF THE LATERAL} AND MEDIAN METHODS. *

Bx THOMAS W. BENFIELD, F.R.C.S., SEYIOR SERGEOY TO THE INEIRMARY.

I Propose to give some account of the cutting operations for stone performed in the infirmary since the year 1851; and although I find it impossible to enter into the details of all the cases in the short space of time which can be allowed to any readers of papers at such a meeting as the present, I think I may venture to intrude upon your time and patience whilst I bring before you some statistics of the operations which have been performed here by the present surgical staff, comparing the methods chiefly adopted here with the lateral adopted elsewhere.

I am led to do this because I believe that the lateral operation, as a general rule, is that which is followed at most of the metropolitan and provincial hospitals, and because so high an authority as Sir Henry Thompson strongly advocates it in preference to the median method. It may, indeed, savour of presumption on my part to oppose, in any way, such authority; and therefore, with my comparatively very small experience, I desire only to state facts which have come under my own observation, and to elicit at this meeting the results of the experience of those gentlemen whose opportunities of observation have equalled and exceeded my own, and whose power of concentration and whose judgment have most probably surpassed what it has been my lot to possess.

It is most difficult to obtain a perfect comparative analysis of a large number of cases, because it needs a most minute and accurate detail of all the circumstances-such as are and constitution, the nature and size of the calculus, the condition of the prostate and urethra; and hence the great obstacle to the conveyance of such knowledge as shall unmistakably point to the safest and best method of renoving stone from the bladder by lithotomy.

Each surgeon may have his own bias and opinion, dependent on his individual success, and more confidence, therefore, in his accustomed mode of operating, than in that which may have been more successful with others. I have performed both lateral and median operations in several cases, haring had only two deaths; and the majority of my operations have been bs the median method, or that advocatel br $\mathrm{Hr}$. Allarton in a pamphlet which he published in the rear 1501 ; and this is the operation which, since its first adoption, bas, with some few exceptions, been the practice of $m y$ colleagues and myself, and, I venture to believe, with rery satisfactory results.

- A pajer redd before the Meeting of the Midland Branch of the British IIedial is: . . ation held in Leicester on the 3 th of Julr, 1869.
It is, as you know, a modification of the Italian opera tion; but I need not detain you by describing it, as it is almost certainly theoretically known to all, and practically to many of you. Sir Henry Thompson admits the applicability of it, especially to children, though I do not gather from his observations that he recommends it in preference to the lateral even in them; for he says, p. 69 in his work on Lithotomy and Lithotrity, published in 1863, " the lateral is generally, and no doubt correctly, held to maintain its superiority, as a rule, over other methods." Though, in speaking of it in children, he says that the deep incision in the urethra and prostate should be made with cleanness and decision, and with suficient freedom to admit the tip of the operator's index-finger with tolerable ease; otherwise he may drive the neck of the bladder along the staff, or slide the finger into the cellular interval between the bladder and rectum. This, at least, shows how much care is requisite even in the lateral operation in children, and brings to $m y$ mind what before appeared to me one of the chief difficulties and sources of anxiety in the median operation in young subjects. Let each one of us be careful how he exult in his own success, for difficulties and contretemps occur to all, and do not necessarily imply want of skill. Ägain, one surgeon may have a long career of success, and yet by one or two subsequent misadventures reduce his previously large percentage of successful cases to the average, or below the average, of the good fortune of others. I have seen a similar accident, against which Sir Henry Thompson warns us, occur in the median operation, in which the urethra was so much torn as to preclude the possibility of passing the finger into the bladder, and in which the patient died without the removal of the stone. Mr. Maunder, of the London Hospital, has described in the Medical Times and Gazette (No. 972, p. 167) the case of a child in which this same accident occurred, with failure in the extraction of the stone, and which also resulted in death. I have made a copy of this case, and shall be glad to read it if required, and I think that its public narration redounds to his honour and credit.

These two cases show the importance of a sufficiently free and clean incision of the urethra in both operations, as the like accident may occur in either; and here I may enforce, en passant, the necessity of being sure of the entrance of the finger into the urethra before any attempt at dilatation of the prostate be employed in the median method. In $\mathrm{Mr}$. Maunder's case, just alluded to, the difficulty he encountered was in passing the finger between the upper surface of the probe used and the under and grooved surface of the staff, in attempting which the prostate and neck of the bladder slipped away in front of his finger; and he, therefore, suggests the use of a grooved director instead of the probe, with a view to incising the prostatic urethra if the resistance at that point be great. Now this is not precisely Allarton's mode of operation; for he recommends the withdrawal of the staff after the introduction of the long probe, and before the introduction of the finger.

The practice which my colleagues and I have generally followed has been not to withdraw the staff until the bladder has been entered by the finger; though I have done this in one case, trusting to the probe alone as a director, because $I$ had great difficulty in inserting my finger without the removal of the staff, and I have seen my colleague, Mr. Marriott, adopt the same plan. I have generally, however, found the staff a most useful director to my finger, and $I$ consider that it, in addition to the finger, forms an admirable dilator of the prostate. Indeed this is the plan which Manzoni, of Verona, adopted; but he gives this necessary caution-viz., not to pass the finger into the prostatic urethra under the staff, but on the patient's right side of it. Now this plan I have always followed, rather indeed curving my forefinger towards the upper surface of the staff, and I am convinced of its importance.

I will now describe the chief structures divided in the two operations.

In the lateral: the skin and superficial fascia; the transversus perinæi muscle and transverse perineal artery; the deep perineal fascia; the membranous urethra and its muscular surroundings; very probably the artery of the bulb; a part of the prostate gland with its urethra; and frequently the acclerator urinæ muscle covering the bulb, and a portion of the levator ani.

In the median: the skin; the superficial and deep fascia; the membranous portion of the urethra and muscular fibres 